\title{
Cooking Surface Temperatures, Steak Thickness, and Quality Grade Effects on Volatile Aroma Compounds
}

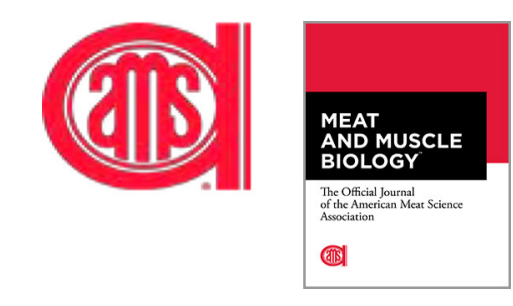

\author{
Chris R. Kerth*, Michael C. Berto, Rhonda K. Miller, and Jeffrey W. Savell \\ Department of Animal Science, Texas A\&M University, College Station, TX 77843, USA \\ *Corresponding author. Email: c-kerth@tamu.edu (Chris R. Kerth)
}

\begin{abstract}
Volatile aroma compounds were evaluated in USDA Top Choice and Select beef top loin steaks cut $1.3 \mathrm{~cm}$ (THIN) or $3.8 \mathrm{~cm}$ (THICK) and cooked on a commercial flat top grill at $177^{\circ} \mathrm{C}$ (LOW) or $232^{\circ} \mathrm{C}$ (HIGH) grill surface temperature. Gas chromatography/mass spectrophotometry was used to evaluate volatile aroma compounds. USDA Select steaks had more 2 -octene and less trimethyl pyrazine in $(P<0.05)$ THIN steaks than THICK steaks, whereas Choice was unaffected by steak thickness $(P>0.05)$. Benzene acetaldehyde was higher and 4-hydroxybenzoic acid was higher in Select LOW grill temperatures compared with Select HIGH grill temperatures, whereas 5-methyl-2-furan carboxaldehyde was only present in Choice HIGH grill temperatures $(P<0.05)$. Two acids, 3 alcohols, 1 aldehyde, 1 alkane, and 1 ketone volatile aroma compound were higher $(P<0.05)$ for LOW compared with HIGH. Conversely, 5 alcohols, 2 aldehydes, 2 alkanes, all 4 furans, 6 ketones, 4 pyrazines, along with 1H-indole, 2 pyrroles, 2 pyridines, and 1 benzene aroma compound were higher $(P<0.05)$ in HIGH compared with LOW. Additionally, 1 alcohol, 2 aldehydes, 1 ketone, 1 sulfur-containing, and 6 other volatile compounds were lower, whereas 1 acid, 1 alcohol, 1 aldehyde, 2 furans, 1 ketone, 3 pyrazines, 1 sulfur-containing, and 1 other volatile compound were higher in the THIN compared with THICK. Some aroma compounds such as 2-butanone, 4-methyl-2-pentanone, 1-ethyl-1H-pyrrole, 1-methyl-1H-pyrrole, and 2-methyl-pyridine were only present in THICK cooked HIGH $(P<0.05)$. Steak thickness and grill temperature are important factors to consider in the development of positive Maillard reaction products. Key findings are that high grill temperatures and/or thick steaks with longer grilling times are required for the development of key Maillard reaction products and many Maillard reaction products were only found in the most severe high-temperature, long-time grilling scenarios.
\end{abstract}

Key words: beef, temperature, thickness, USDA Quality Grade, volatiles

Meat and Muscle Biology 5(1): 47, 1-10 (2021) doi:10.22175/mmb.12929

Submitted 8 June $2021 \quad$ Accepted 2 November 2021

\section{Introduction}

Taste and smell are contributors to our evaluation of the food we eat and the world around us; these senses have developed to enable our survival and determine our preferences. The attributes of food items are perceived in the order of appearance, odor/aroma, consistency and texture, and flavor (Meilgaard et al., 2006). These overlap and provide multiple stimuli that contribute to the overall eating experience for a food or beverage item. For sensory purposes, flavor is defined and measured as the combined impressions perceived via the chemical senses from a product in the mouth (odor/aroma and flavor), eliminating appearance and texture from the observation. In the mouth, the senses of olfaction and gustation combine to produce flavor perception (Small et al., 1997). Because these 2 senses are tied together for the detection of flavors, if one is inhibited, the perception of flavor will be greatly diminished. Olfactory senses are responsible for detecting aroma or volatile compounds. These odors are a lot less defined and straightforward than gustatory senses and take training to identify and detect because there are thousands of possible smells (Meilgaard et al., 2006). Volatiles have been analyzed for nearly half 
a century to determine what chemical compounds are present and to relate them to sensory descriptors (Shahidi, 1998).

The thickness of steaks found in retail and foodservice has been previously reported and varies a great deal, being very dependent on consumer preferences and cuts of meat (Brooks et al., 2000; Guelker et al., 2013). Miller et al. (2019) have reported the effect of steak thickness, cook surface temperature, and quality grade on consumer and descriptive sensory attributes of the steaks in the current research project reported here. We also investigated the thermophysical properties (Gardner et al., 2020) of steaks from Miller et al. (2019) cooked under high and low grill temperatures to determine the physical differences among the treatments. Researchers have reported on cooking temperature effects on palatability (Cross et al., 1976; Knize et al., 1994; Skog et al. 1995) but did not include volatile aroma compounds. Our lab (Wall et al., 2019) has done some previous work investigating the specific impact that grill temperature has on the sensory and volatile compounds of steaks. Additionally, Kerth (2016) reported on the volatile compounds from steaks of different thicknesses cooked at different grill temperatures, but USDA Quality Grade was not a part of that project. Research that examines both thickness and grill temperature factors and their subsequent effect on volatile aroma compounds as they relate to both trained and consumer sensory traits has not been reported.

The objective of this part of the project was to create varying levels of beef flavor by cutting Top Choice and Select top loin steaks $1.3 \mathrm{~cm}$ and $3.8 \mathrm{~cm}$ thick and cooking them at either $177^{\circ} \mathrm{C}$ or $232^{\circ} \mathrm{C}$. Steaks were evaluated using gas chromatography (GC)/mass spectroscopy (MS) to explain the volatile chemicals in beef flavor. We hypothesized that by using the different thicknesses and temperatures within Top Choice and Select quality grades, the resulting time and temperature combination during cooking would create differing levels of volatile aroma compounds in Top Choice and Select beef top loin steaks.

\section{Materials and Methods}

\section{Experimental design and meat preparation}

One beef strip loin (Institutional Meat Purchase Specifications \#180) from 32 random animals was removed from carcasses on 2 selection trips from a commercial beef processing facility. USDA Select $(n=16)$ and upper two-thirds USDA Choice $(n=16)$ carcasses were selected after grading by a USDA grader and by Texas A\&M Meat Science personnel trained in grading to confirm USDA Quality Grade (USDA, 1996). Vacuum-packaged strip loins were transported $\left(4^{\circ} \mathrm{C}\right)$ to Texas A\&M University Rosenthal Meat Technology Center and stored at $4^{\circ} \mathrm{C}$ until the loins reached $14 \mathrm{~d}$ post-packaging at the plant. Because steak thickness was a primary treatment, the strip loins were placed in the freezer $\left(-40^{\circ} \mathrm{C}\right)$ after aging to allow uniform and precise cutting of the steaks on a band saw. Strip loins were frozen at $-40^{\circ} \mathrm{C}$ for a minimum of $24 \mathrm{~h}$ and held at $-40^{\circ} \mathrm{C}$ until slicing on the band saw. To randomize the steak thickness in each strip loin, a drawing of each loin was made on paper, assigning a cooking temperature and a steak thickness to each of the 8 portions. During cutting, each steak was cut the assigned steak thickness from the randomized assignment. After intact strip loins were frozen, 1 strip loin from each animal was divided into its 8 portions with its assignment to 2 cooking temperatures $\left(\mathrm{HIGH}=232^{\circ} \mathrm{C}\right.$ or $\left.\mathrm{LOW}=177^{\circ} \mathrm{C}\right)$ and 2 steak thicknesses $($ THIN $=1.3 \mathrm{~cm}$ or THICK $=3.8 \mathrm{~cm}$ ) so that 2 steaks per subclass (temperature $\times$ steak thickness) were obtained per strip loin. One of each replicate subclass within a loin was assigned to the trained sensory panel and the other to consumer panels.

Steaks were trimmed to $0.25 \mathrm{~cm}$ external fat, labeled, and vacuum-packaged individually in vacuum bags (B2470, Sealed Air Corporation, Charlotte, NC) with an oxygen transmission rate of 3 to $6 \mathrm{cc}$ at $4{ }^{\circ} \mathrm{C}\left(\mathrm{m}^{2}, 24 \mathrm{~h}\right.$ at $4^{\circ} \mathrm{C}, 0 \%$ relative humidity $\left.[\mathrm{RH}]\right)$ and a water vapor transmission rate of 0.5 to $0.6 \mathrm{~g}$ at $38^{\circ} \mathrm{C}(100 \% \mathrm{RH}$, $0.6 \mathrm{~m}^{2}, 24 \mathrm{~h}$ ). Once packaged, steaks were boxed and placed in frozen storage at $-23^{\circ} \mathrm{C}$ for up to 7 mo until analyses were performed. For each analysis, individual steaks were selected with each treatment combination represented and thawed in refrigerated $\left(4^{\circ} \mathrm{C}\right)$ storage for $24 \mathrm{~h}$. Steaks for all cooked analyses were placed on a grill, turned when the internal temperature reached $37^{\circ} \mathrm{C}$, and removed when the internal temperature reached $71^{\circ} \mathrm{C}$ (medium degree of doneness; AMSA, 2015).

Steaks were cooked on a 2.54-cm-thick flat top (Star Max 536TGF $91.44 \mathrm{~cm}$ Countertop Electric Griddle, Star International Holdings Inc., St. Louis, MO) set at either $177^{\circ} \mathrm{C}$ or $232^{\circ} \mathrm{C}$. Internal steak temperatures were monitored by iron-constantan thermocouples (Omega Engineering, Norwalk, CT) inserted into the steak geometric center. Surface temperatures of the grilled steak surface (at the time of turning and when it was removed from the grill) and the grill surface in the location where the steak was placed (initially, at the time of turning, and when the steak was removed) were taken with an iron-constantan surface 
probe (Model 88402E, Omega Engineering). These measurements were used to determine the way the grill and steak surface temperature changed during cooking due to the evaporative cooling caused by water loss of the steak during the cooking process, and temperatures were displayed using a thermometer (Omega HH501BT Type T thermometer, Omega Engineering). Each steak was prepared for consumer sensory evaluation in State College, PA, and the sensory results are reported in detail by Miller et al. (2019).

\section{Cooked beef volatile aroma compounds}

Volatiles were captured from the same steaks evaluated by the consumer panelists in State College, PA, prepared using the methods outlined by AMSA (2015). After samples were prepared for consumers, approximately $75 \mathrm{~g}$ of the cooked beef cubes were placed in foil with a tag separated from the meat samples. Samples were placed in liquid nitrogen and then transported on dry ice to the Kleberg Animal and Food Sciences Center in College Station, TX, and stored for less than $2 \mathrm{wk}$ at $-80^{\circ} \mathrm{C}$ until volatile analysis.

For volatile analysis, samples were placed in heated glass canning jars ( $473 \mathrm{~mL}$, Newell Brands, Inc., Atlanta, GA) with a Teflon lid and then set in a water bath at $60^{\circ} \mathrm{C}$ and allowed to thaw for $1 \mathrm{~h}$. The headspace was collected with a solid-phase micro-extraction (SPME) portable field sampler (Supelco 504831, $75 \mu \mathrm{m}$ carboxen/polydimethylsiloxane, Sigma-Aldrich, St. Louis, MO) for $2 \mathrm{~h}$ after the sample reached $60^{\circ} \mathrm{C}$. After static headspace collection, the SPME was injected in the injection port of the GC (Agilent Technologies 7820 Series Gas Chromatograph, Santa Clara, CA), where the sample was desorbed at $280^{\circ} \mathrm{C}$. The sample was then loaded in splitless mode onto a multidimensional gas chromatograph into the first column $(30 \mathrm{~m} \times 0.53 \mathrm{~mm}$ ID/BPX5 [5\% phenyl polysilphenylene-siloxane] $\times 0.5 \mu \mathrm{m}$, SGE Analytical Sciences, Austin, TX) and then a second column ([30 m × $0.53 \mathrm{~mm}$ ID; BP20-polyethylene glycol] $\times$ $0.50 \mu \mathrm{m}$, SGE Analytical Sciences). The GC column is then split into different transfer lines at a 3-way valve inside the GC, with 1 going to the single-quadrupole mass spectrometer (Agilent Technologies 5975 Series MSD) and 2 going to the 2 humidified sniff ports with glass nose pieces heated to $115^{\circ} \mathrm{C}$. The $\mathrm{GC}$ oven temperature started at $40^{\circ} \mathrm{C}$ and increased at a rate of $7^{\circ} \mathrm{C} / \mathrm{min}$ until reaching $260^{\circ} \mathrm{C}$. The MS was run with an electron multiplier voltage of $1,259 \mathrm{~V}$, source temperature of $230^{\circ} \mathrm{C}$, quadrupole temperature of $150^{\circ} \mathrm{C}$, mass range $\mathrm{m} / \mathrm{z}$ of $50-550$, and scan rate of $2.9 \mathrm{scans} / \mathrm{s}$. Each chromatogram was integrated using the RTE integrator, and when peaks were isolated, retention time, a quality value (a measure of confidence in the final identification on a scale of 1 to 100), calculated area under the curve, and 1 of the top 3 identified compounds compared with the National Institute of Standards and Technology (NIST) Library were then use for statistical analyses. Retention times of all compounds were compared across all samples, and any compound lacking a retention time within $0.2 \mathrm{~min}$ of the other samples or a quality score of lower than 70 were removed from the analyses. A minimum area under the curve of 500 was used as the cutoff for the lower detection level. Mass spectrometer total ion counts of the area under the curve for each peak were $\ln _{(x+1)}$ (natural log of the area under the curve +1 to account for any that had a value of 0 ) transformed to normalize and are reported here as $\ln _{(\mathrm{x}+1)}$-transformed least-squares means.

\section{Statistical analyses}

Cooking data and volatile aroma compound data were analyzed as a split-plot design with replicate as a random effect and the fixed effect USDA Quality Grade (USDA Select or Choice quality grade) in the whole plot with fixed effects steak thickness (THIN or THICK) and grill temperature (LOW or HIGH grill temperature) and all 2-way interactions in the split-plot. The error term for the whole plot was the replicate within quality grade, and the residual error was used for split-plot factors using the following model:

$$
\begin{aligned}
Y_{h i j k}= & \mu+\theta_{h}+\alpha_{i}+\epsilon_{i(h)}^{W}+\beta_{j}+\gamma_{k}+(\alpha \beta)_{i j}+(\alpha \gamma)_{i k} \\
& +(\beta \gamma)_{j k}+\epsilon_{j k(h i)}^{S}
\end{aligned}
$$

where $\theta_{h}=$ the $h$ th replicate, $\alpha_{i}=$ the $i$ th quality grade, $\beta_{j}=$ the $j$ th steak thickness, $\gamma_{k}=$ the $k$ th grill temperature, and $\epsilon_{i(h)}^{W}$ and $\epsilon_{j k(h i)}^{S}=$ the whole- and split-plot error, respectively. Restricted maximum likelihood was used to model the variance component with the same structure for all compounds. When significant $(P<0.05)$ main or interaction effects were detected in the analysis of variance, least-squares means were separated using a Fisher's protected least significant difference (a 2-sample $t$ test) in JMP version 15 (SAS Institute, Inc., Cary, NC).

\section{Results and Discussion}

\section{Cooking surface and steak temperatures}

USDA Quality Grade and its interaction with steak thickness or grilling time were not affected by cooking 
temperature or time $(P<0.05)$. Steak thickness, grill temperature setting, and their interaction effects on actual grill and steak surface temperature variations are shown in Figure 1. As expected, there was no difference $(P>0.05)$ between steak thicknesses for the initial or flip grill surface temperature, whereas those with LOW temperatures were lower compared with those with HIGH temperatures $(P<0.05)$. The steak surface temperature at the time of flipping was higher $(P>$ 0.05 ) for THICK steaks, as they had more grill surface contact time that resulted in more heat surface dehydration, thus limiting surface evaporative cooling compared with THIN steaks. As might be expected, the steak surface temperature was higher $(P<0.05)$ for steaks grilled at the HIGH temperature compared with the LOW temperature at the time of flipping. The final steak surface temperature was similar $(P>0.05)$ between THIN steaks regardless of the grill temperature, but THICK steak surface temperature was higher $(P<0.05)$ than THIN steak surface temperature when grill temperature was HIGH. The main effects of steak thickness as well as grill temperature both affected the final grill surface temperature and cooking losses, with THIN steaks having lower final grill temperatures and cooking losses compared with THICK steaks and LOW grill temperatures having lower final grill temperatures and cooking losses than HIGH $(P<0.05)$ grill temperatures. Kerth (2016) found a difference between grill temperature across the 3 steak thickness treatments, with the $3.8-\mathrm{cm}$-thick steaks having a much higher grill temperature. The difference in the current study was likely the grill, which was designed to hold

Temperatures and Cook Loss

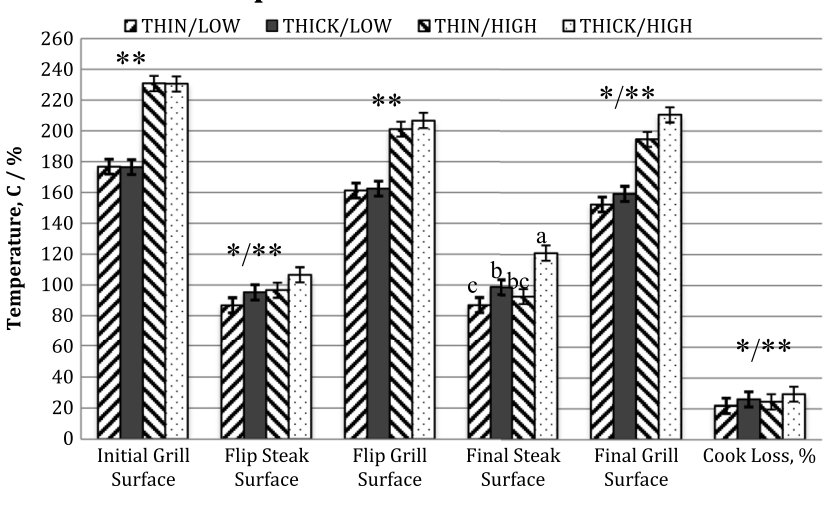

Figure 1. Steak thickness by grill temperature main and interaction effects on steak and grill surface temperatures. THIN $=1.3$-cm-thick steaks, THICK $=3.8$-cm-thick steaks, $\mathrm{LOW}=177^{\circ} \mathrm{C}$ grill temperature, $\mathrm{HIGH}=$ $232^{\circ} \mathrm{C}$ grill temperature. $*$ Indicates significant $(P<0.05)$ steak thickness main effect differences, and $* *$ indicates significant $(P<0.05)$ grill surface temperature main effect differences within a measured trait. ${ }^{\mathrm{a}-\mathrm{c}} \mathrm{Bars}$ with different letters indicate steak thickness by grill temperature interaction leastsquares means within a trait are significantly different $(P<0.05)$. and react to temperature changes via thermostatic controls. Additionally, Kerth (2016) used a cast iron skillet on a gas stove to cook the steaks with the possibility that the different cooking methods and heat sources may have caused these differences between the studies.

THICK steaks took a longer $(P<0.05$; Figure 2$)$ time to cook on side 1 and side 2 compared with THIN steaks, but cooking time was not affected $(P>0.05)$ by grill temperature on either side individually. Furthermore, grill temperature did not $(P>0.05)$ impact total cooking time when steaks were cut THIN, but when steaks were cut THICK, cooking time was longer $(P<0.05)$ at LOW grill temperatures than HIGH grill temperatures. Kerth (2016) found near-identical results showing that thicker steaks all cooked longer and lower temperature grill required more time to cook. One difference is that they found the second side took significantly longer to cook than the first side, and the current study found that the time was almost similar for both sides of the steak; again, this is probably due to the cooking method, wherein they used cast iron skillets and we used the thermostatic commercial grill.

Berry and Bigner (1995) reported that beef loin steaks cooked at $232^{\circ} \mathrm{C}$ had a faster cook time than steaks cooked at $204^{\circ} \mathrm{C}$ but the same cook loss. Additionally, steaks cooked at $204^{\circ} \mathrm{C}$ or $232^{\circ} \mathrm{C}$ surface cook temperature did not differ in connective tissue, tenderness, or beef flavor intensity. It is important to note that the cooking methods were slightly different than in the current study, and steaks were cooked on a slatted grill; thus, the temperature range varied more than the grill setting itself. Wall et al. (2019) indicated

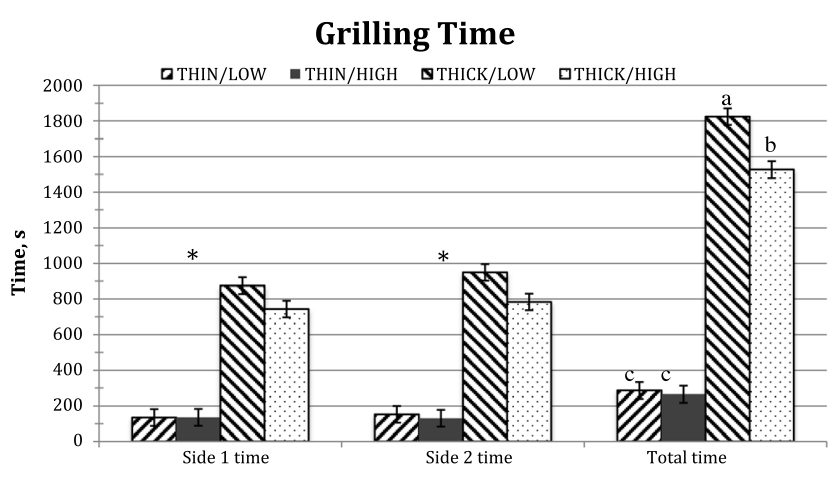

Figure 2. Steak thickness by grill temperature main and interaction effects on grilling time. THIN $=1.3-\mathrm{cm}$-thick steaks, THICK $=3.8-\mathrm{cm}$ thick steaks, $\mathrm{LOW}=177^{\circ} \mathrm{C}$ grill temperature, $\mathrm{HIGH}=232^{\circ} \mathrm{C}$ grill temperature. * Indicates significant $(P<0.05)$ steak thickness main effect mean differences within a measured trait. No significant $(P>0.05)$ grill temperature main effects were observed. ${ }^{\mathrm{a}-\mathrm{c}} \mathrm{Bars}$ with different letters indicate steak thickness by grill temperature interaction least-squares means within a trait are significantly different $(P<0.05)$. 
that grilling at $232^{\circ} \mathrm{C}$ resulted in a shorter side 2 and total cooking time compared with $177^{\circ} \mathrm{C}$.

The presence of some volatiles in this study bears out the differences in surface temperatures and cooking times. For example, 2-furan carboxaldehyde tended $(P=$ 0.078 ) to be and 4-methyl-2-pentanone, 1H-indole, 1-ethyl-1H-pyrrole, 1-methyl-pyrrole, 2-methyl-pyridine, 2,3-diethyl-5-methyl-pyrazine were $(P<0.007)$ present only in HIGH grill temperatures and THICK steaks. This indicates that the compounds that require the most energy to form are present in only the most extreme conditions of time and temperature.

\section{Volatile aroma compounds}

There may be only a small fraction, in the range of 10 to 50 compounds, of the hundreds of measured volatiles that impact the aroma and flavor of foods (Mottram, 1998). In the present study, a total of 111 volatile aroma compounds were identified by the mass spectrometer NIST Library search. In previous research, Luckemeyer (2015) found 248 volatile aroma compounds. Luckemeyer (2015) used multiple muscles and cooking methods that would expectantly result in a higher number of volatile aroma compounds. In another study, Glascock (2014) reported 149 volatile aroma compounds. Although Glascock (2014) had multiple cuts, the cooking temperature was lower than in the present study. Only those 46 compounds that were confirmed to be present by library search and retention time comparison against literature values and were statistically significant $(P<0.05)$ for main or interaction effects are reported here.

There were no USDA Quality Grade main effects on volatile aroma compounds in this study $(P>0.05)$, and therefore, they are not included in the discussion. This is somewhat surprising because the companion paper to the present study (Miller et al., 2019) did find some very small ( 0.1 to 0.3 on a 16 -point scale) differences in beef identity, fat-like, umami, sweet, and sour trained descriptive sensory attributes between USDA Top Choice and Select quality grades. Nevertheless, Legako et al. (2015) reported that no differences existed in volatile aroma compound levels within the longissimus muscle between USDA Upper 2/3 Choice or Select. Sepulveda et al. (2019), however, found that the primary difference in volatiles affected by USDA Quality Grade was in the USDA Prime grade, whereas Top Choice and Select had very few differences.

Volatile aroma compounds were categorized by volatile chemical type into 9 categories to understand the effects of steak thickness and cook surface temperature main and interaction effects on volatile aroma compound levels in top loin steaks (Table 1). Only those that had significant $(P<0.05)$ thickness and/or grill temperature main effects and their interactions are shown. Although 4-hydroxy-benzoic acid was higher $(P=0.043)$ in THIN steaks compared with THICK steaks, the opposite was true for hexanoic acid $(P=0.018)$. Acetic acid (sour, vinegar aroma) and butanoic acid (sweaty and rancid aroma; Kerth and Miller, 2015) values were higher $(P=0.033$ and 0.042 , respectively) in steaks cooked to LOW compared with HIGH but were not affected $(P>0.05)$ by steak thickness or the interaction. Wall et al. (2019) found no differences in any acid volatiles when grilled at $177^{\circ} \mathrm{C}, 205^{\circ} \mathrm{C}$, or $232^{\circ} \mathrm{C}$, and Kerth (2016) reported that no acids were present when steaks were grilled at the same 3 temperatures. Gardner and Legako (2018) reported that acetic acid concentrations declined significantly as the degree of doneness increased from $25^{\circ} \mathrm{C}$ to $77^{\circ} \mathrm{C}$ in USDA Prime steaks, which would indicate a reduction in lipid degradation products in favor of more Maillard reaction products.

Alcohol volatile compounds are formed by the degradation of fatty acids during the cooking process (Shahidi, 1998). In general, they mostly provide fragrant, plant-like, rancid, and earthy odors (Cadwallader et al., 1995), which tend to make relatively small contributions to the overall flavor of cooked meat (Ba et al., 2012). Interestingly 1-octen-3-ol (earthy), 1-pentanol (bread and cereal aroma), and 2-(hexyloxy)-ethanol compounds were higher when cooked at LOW temperatures whereas 3-heptanol, 3-octanol, 4-methyl-3heptanol, 4-methyl-phenol, and phenol compounds (bitter, herbaceous, phenolic, fecal, and irritating - all negative aromas; Burdock, 2010) were higher when the steaks were cooked at HIGH temperatures $(P<$ 0.05). Gardner and Legako (2018) reported a reduction in 1-octen-3-ol in USDA Prime ground beef as the degree of doneness increased, and Wall et al. (2019) showed a tendency for 1-octen-3-ol to be higher in steaks cooked at a lower temperature. Additionally, 2-(hexyloxy)-ethanol values were higher for THIN compared with THICK steaks, and phenol values were higher for THICK compared with THIN steaks $(P=0.001$ and 0.011 , respectively). No interaction effects were found for any alcohol compounds $(P>0.05)$.

The volatile compound 2-hexenal (green apple) was found to be higher $(P=0.004)$ in LOW-temperature steaks, whereas benzaldehyde $(P=0.034$; bitter almond) and undecanal $(P=0.013$; buttery, soapy) were higher in HIGH-temperature steaks $(P<0.05)$. When comparing thicknesses of steaks, 2,4-decadienal 
Table 1. Least-squares means and SEM of volatile aroma compounds reported as $\log _{n(x+1)}$-transformed total ion counts under the curve of the chromatogram by compound type for steak thickness and grill temperature treatments

\begin{tabular}{|c|c|c|c|c|c|c|c|c|c|c|c|}
\hline \multirow[b]{2}{*}{ Volatile } & \multicolumn{2}{|c|}{$\mathrm{THIN}^{1}$} & \multicolumn{2}{|c|}{ THICK } & \multirow[b]{2}{*}{ SEM } & \multicolumn{3}{|c|}{$P>F$} & \multirow[b]{2}{*}{$\begin{array}{l}\text { GC Retention } \\
\text { Time, min } \\
\end{array}$} & \multirow[b]{2}{*}{$\mathrm{LRI}^{2}$} & \multirow[b]{2}{*}{$\begin{array}{l}\text { Published Aroma } \\
\text { Descriptor }\end{array}$} \\
\hline & LOW & HIGH & LOW & HIGH & & Thick & Temp & $\begin{array}{l}\text { Thick } \times \\
\text { Temp }\end{array}$ & & & \\
\hline \multicolumn{12}{|l|}{ Acids } \\
\hline 4-hydroxy-benzoic acid & 1.0 & 2.7 & 0.8 & 0.6 & 0.58 & 0.043 & 0.18 & 0.10 & 21.7 & $1,355.7$ & Sweet, acrid ${ }^{+}$ \\
\hline Acetic acid & 8.3 & 5.7 & 7.1 & 5.5 & 1.02 & 0.50 & 0.033 & 0.61 & 12.3 & 975.2 & Sour, vinegar ${ }^{*}$ \\
\hline Butanoic acid & 2.2 & 1.4 & 4.0 & 1.6 & 0.83 & 0.21 & 0.042 & 0.32 & 15.5 & $1,094.6$ & Sweaty, rancid* \\
\hline Hexanoic acid & 5.3 & 3.9 & 7.1 & 6.6 & 1.02 & 0.018 & 0.33 & 0.65 & 19.4 & $1,252.8$ & Sweet, rancid ${ }^{+}$ \\
\hline \multicolumn{12}{|l|}{ Alcohols } \\
\hline 1-octen-3-ol & 9.3 & 5.3 & 8.9 & 4.0 & 1.15 & 0.43 & 0.001 & 0.69 & 14.1 & $1,039.5$ & Mushroom, earthy* \\
\hline 1-pentanol & 9.4 & 8.3 & 9.1 & 6.6 & 0.85 & 0.23 & 0.03 & 0.37 & 9.2 & 863.2 & Bread, cereal $^{*}$ \\
\hline 2-(hexyloxy)-ethanol & 12.4 & 11.0 & 9.4 & 7.0 & 0.81 & 0.001 & 0.016 & 0.47 & 17.4 & $1,168.0$ & Not known \\
\hline 3-heptanol & 0.0 & 1.7 & 0.0 & 0.3 & 0.44 & 0.10 & 0.013 & 0.10 & 11.3 & 739.8 & Herbaceous, bitter ${ }^{+}$ \\
\hline 3-octanol & 0.4 & 0.8 & 0.0 & 1.2 & 0.43 & 0.14 & 0.046 & 0.49 & 13.8 & $1,029.5$ & Nutty, herbaceous ${ }^{+}$ \\
\hline 4-methyl-3-heptanol & 0.0 & 0.6 & 0.0 & 0.9 & 0.35 & 0.62 & 0.030 & 0.61 & 13.9 & $1,029.8$ & Cresol, phenolic ${ }^{+}$ \\
\hline 4-methyl-phenol & 3.7 & 5.5 & 3.2 & 7.2 & 0.95 & 0.53 & 0.001 & 0.24 & 22.9 & $1,413.7$ & Fecal, horse stable ${ }^{*}$ \\
\hline Phenol & 2.7 & 3.3 & 3.3 & 7.1 & 0.90 & 0.011 & 0.011 & 0.06 & 21.6 & $1,355.1$ & Sweet, irritating $^{+}$ \\
\hline \multicolumn{12}{|l|}{ Aldehydes } \\
\hline 2-hexenal & 1.0 & 0.3 & 2.0 & 0.0 & 0.50 & 0.46 & 0.004 & 0.17 & 10.0 & 894.1 & Green apple, bitter ${ }^{*}$ \\
\hline 2,4-decadienal & 2.5 & 3.9 & 5.7 & 4.4 & 0.93 & 0.043 & 0.94 & 0.12 & 21.9 & $1,367.2$ & Oily, orange $^{+}$ \\
\hline Acetaldehyde & 3.2 & 3.6 & 2.0 & 1.2 & 0.85 & 0.030 & 0.81 & 0.42 & 2.6 & 478.2 & Fresh, green ${ }^{*}$ \\
\hline Benzaldehyde & 5.0 & 7.2 & 8.4 & 10.7 & 1.10 & 0.001 & 0.034 & 0.96 & 15.0 & $1,072.3$ & Bitter almond $^{+}$ \\
\hline Undecanal & 7.1 & 8.8 & 6.8 & 9.6 & 0.96 & 0.78 & 0.013 & 0.52 & 22.2 & $1,304.2$ & Buttery, soapy ${ }^{*}$ \\
\hline \multicolumn{12}{|l|}{ Alkanes } \\
\hline Dodecane & 2.8 & 6.5 & 4.7 & 7.8 & 1.12 & 0.13 & 0.002 & 0.75 & 17.1 & $1,157.5$ & Floral, fragrant ${ }^{*}$ \\
\hline Heptane & 3.5 & 1.6 & 4.5 & 2.3 & 0.90 & 0.31 & 0.018 & 0.86 & 4.3 & 646.6 & Not known \\
\hline Undecane & 0.7 & 4.6 & 1.8 & 5.9 & 0.91 & 0.16 & 0.001 & 0.92 & 14.7 & $1,029.8$ & Not known \\
\hline \multicolumn{12}{|l|}{ Furans } \\
\hline 2-furancarboxaldehyde & 0.8 & 1.0 & 0.6 & 2.6 & 0.66 & 0.15 & 0.039 & 0.078 & 12.9 & 996.8 & Brown, nutty, bread ${ }^{*}$ \\
\hline 2-furanmethanol & 0.0 & 1.2 & 0.4 & 3.5 & 0.62 & 0.010 & 0.001 & 0.19 & 16.3 & $1,123.4$ & Burnt, cooked sugar ${ }^{+}$ \\
\hline 2-octylfuran & 0.0 & 1.4 & 0.8 & 3.6 & 0.62 & 0.011 & 0.002 & 0.26 & 19.9 & $1,277.0$ & Not known \\
\hline $\begin{array}{l}\text { 5-methyl-2- } \\
\text { furancarboxaldehyde }\end{array}$ & 0.0 & 0.6 & 0.2 & 1.3 & 0.40 & 0.21 & 0.030 & 0.53 & 15.5 & $1,091.7$ & Sweet, caramel ${ }^{+}$ \\
\hline \multicolumn{12}{|l|}{ Ketones } \\
\hline 1-octen-3-one & 0.4 & 0.0 & 1.6 & 0.3 & 0.45 & 0.075 & 0.047 & 0.26 & 12.9 & 995.4 & Mushroom* \\
\hline 2-decanone & 1.5 & 6.7 & 3.7 & 7.8 & 0.94 & 0.063 & 0.001 & 0.56 & 17.9 & $1,188.7$ & Orange floral $^{+}$ \\
\hline 2-nonanone & 0.8 & 7.5 & 3.3 & 8.2 & 0.86 & 0.051 & 0.001 & 0.26 & 15.6 & $1,096.1$ & Cheesy dairy-butter ${ }^{*}$ \\
\hline 2-octanone & 1.1 & 5.3 & 1.7 & 6.3 & 0.88 & 0.31 & 0.001 & 0.86 & 13.4 & 999.3 & Floral, green, fruity ${ }^{+}$ \\
\hline 2-pentanone & 1.8 & 2.7 & 1.8 & 4.7 & 0.84 & 0.20 & 0.018 & 0.19 & 5.1 & 704.4 & Fruity, banana* \\
\hline 3-heptanone & 0.0 & 1.3 & 0.3 & 1.5 & 0.51 & 0.56 & 0.013 & 0.93 & 10.1 & 894.6 & Melon, banana ${ }^{+}$ \\
\hline $\begin{array}{l}\text { 4-hydroxy-4-methyl-2- } \\
\text { pentanone }\end{array}$ & 4.4 & 2.6 & 0.3 & 0.9 & 0.74 & 0.001 & 0.42 & 0.09 & 11.5 & 753.4 & Fruity, pleasant ${ }^{\#}$ \\
\hline 4-methyl-2-pentanone & $0.0^{\mathrm{b}}$ & $0.0^{\mathrm{b}}$ & $0.3^{\mathrm{b}}$ & $2.6^{\mathrm{a}}$ & 0.44 & 0.001 & 0.006 & 0.006 & 6.2 & 563.4 & Fruity, ethereal $^{+}$ \\
\hline \multicolumn{12}{|l|}{ Pyrazines } \\
\hline 2-acetyl-3-methyl-pyrazine & 0.3 & 1.9 & 0.2 & 1.6 & 0.53 & 0.69 & 0.003 & 0.83 & 18.5 & $1,215.4$ & Nutty, roasted ${ }^{\#}$ \\
\hline 2-ethyl-5-methyl-pyrazine & 3.9 & 7.2 & 8.7 & 9.8 & 0.89 & 0.001 & 0.008 & 0.20 & 14.0 & $1,036.9$ & Coffee, nutty ${ }^{*}$ \\
\hline $\begin{array}{l}\text { 2-methyl-6-(1-propenyl)- } \\
\text { pyrazine }\end{array}$ & 0.0 & 1.5 & 0.8 & 3.3 & 0.66 & 0.040 & 0.002 & 0.46 & 19.7 & $1,268.4$ & Not known \\
\hline $\begin{array}{l}\text { 2,3-diethyl-5-methyl- } \\
\text { pyrazine }\end{array}$ & $0.0^{\mathrm{b}}$ & $0.0^{\mathrm{b}}$ & $0.0^{\mathrm{b}}$ & $1.2^{\mathrm{a}}$ & 0.32 & 0.047 & 0.045 & 0.045 & 17.3 & $1,164.9$ & Nutty, roasted ${ }^{+}$ \\
\hline
\end{tabular}


Table 1. (Continued)

\begin{tabular}{|c|c|c|c|c|c|c|c|c|c|c|c|}
\hline \multirow[b]{2}{*}{ Volatile } & \multicolumn{2}{|c|}{ THIN $^{1}$} & \multicolumn{2}{|c|}{ THICK } & \multirow[b]{2}{*}{ SEM } & \multicolumn{3}{|c|}{$\mathrm{P}>\mathrm{F}$} & \multirow[b]{2}{*}{$\begin{array}{l}\text { GC Retention } \\
\text { Time, min }\end{array}$} & \multirow[b]{2}{*}{$\mathrm{LRI}^{2}$} & \multirow[b]{2}{*}{$\begin{array}{c}\text { Published Aroma } \\
\text { Descriptor }\end{array}$} \\
\hline & LOW & $\mathrm{HIGH}$ & LOW & $\mathrm{HIGH}$ & & Thick & Temp & $\begin{array}{c}\text { Thick } \times \\
\text { Temp }\end{array}$ & & & \\
\hline \multicolumn{12}{|l|}{$\overline{\text { Sulfur-containing }}$} \\
\hline 1-acetylthiazole & 4.6 & 3.6 & 1.9 & 0.9 & 0.83 & 0.001 & 0.19 & 0.95 & 16.9 & $1,148.6$ & Green onion, grassy ${ }^{+}$ \\
\hline Methanethiol & 3.8 & 3.0 & 4.8 & 5.6 & 0.95 & 0.049 & 0.95 & 0.36 & 2.6 & 480.2 & Garlic, cabbage $^{+}$ \\
\hline \multicolumn{12}{|l|}{ Other } \\
\hline 1H-indole & $0.0^{\mathrm{c}}$ & $3.9^{\mathrm{b}}$ & $0.4^{\mathrm{c}}$ & $8.6^{\mathrm{a}}$ & 0.71 & 0.001 & 0.001 & 0.002 & 27.8 & $1,669.1$ & Fecal, mothball ${ }^{*}$ \\
\hline 1-ethyl-1H-pyrrole & $0.0^{\mathrm{b}}$ & $0.0^{\mathrm{b}}$ & $0.0^{\mathrm{b}}$ & $4.4^{\mathrm{a}}$ & 0.47 & 0.001 & 0.001 & 0.001 & 8.9 & 853.6 & Not known \\
\hline 1-methyl-1H-pyrrole & $0.0^{\mathrm{b}}$ & $0.0^{\mathrm{b}}$ & $0.0^{\mathrm{b}}$ & $2.9^{\mathrm{a}}$ & 0.53 & 0.16 & 0.001 & 0.001 & 7.4 & 800.2 & Herbal, smokey\# \\
\hline 1-octene & 6.2 & 5.1 & 3.5 & 2.6 & 0.96 & 0.005 & 0.27 & 0.88 & 7.0 & 759.4 & Gasoline $^{+}$ \\
\hline 2-methyl-pyridine & $0.0^{\mathrm{b}}$ & $0.5^{\mathrm{b}}$ & $0.3^{\mathrm{b}}$ & $4.5^{\mathrm{a}}$ & 0.58 & 0.001 & 0.001 & 0.001 & 9.5 & 875.3 & Bitter, sweaty ${ }^{\#}$ \\
\hline Ethylbenzene & 0.4 & 1.3 & 0.3 & 2.8 & 0.66 & 0.27 & 0.007 & 0.21 & 9.3 & 869.5 & Gasoline $e^{\#}$ \\
\hline Pyridine & 0.0 & 0.9 & 0.6 & 2.7 & 0.56 & 0.029 & 0.005 & 0.25 & 8.1 & 827.1 & Penetrating $^{+}$ \\
\hline Styrene & 6.1 & 7.6 & 7.4 & 9.8 & 0.88 & 0.063 & 0.037 & 0.39 & 11.0 & 927.5 & Sweet, balsamic ${ }^{*}$ \\
\hline
\end{tabular}

$\mathrm{GC}=$ gas chromatography; $\mathrm{SEM}=$ standard error of the mean; Temp $=$ temperature; Thick $=$ thickness.

${ }^{1} \mathrm{THIN}=1.3$-cm-thick steaks, $\mathrm{THICK}=3.8$-cm-thick steaks, $\mathrm{LOW}=177^{\circ} \mathrm{C}$ grill temperature, $\mathrm{HIGH}=232^{\circ} \mathrm{C}$ grill temperature

${ }^{2}$ LRI $=$ linear retention index (Van Den Dool and Kratz, 1963).

${ }^{\mathrm{a}-\mathrm{c}}$ Least squares means in a row with different superscripts differ $(P<0.05)$.

${ }^{*}$ Kerth and Miller, 2015.

${ }^{+}$Burdock, 2010.

${ }^{\#}$ Kim et al., 2019.

( $P=0.043$; oily, orange $)$ and benzaldehyde $(P=0.034)$ were higher in THICK rather than THIN steaks. Acetaldehyde, which has a fresh or green aroma descriptor, was higher for THIN compared with THICK $(P=$ $0.030)$. Some of these aldehydes are a result of lipid degradation, which would naturally be higher at lower time and grill temperature, resulting in more moisture being on the surface, resulting in their higher concentration (Feng et al., 2020).

Dodecane (floral or fragrant aroma; Kerth and Miller, 2015) and undecane values were higher for steaks cooked at a grill temperature of HIGH compared with LOW, but heptane values were higher for steaks cooked at LOW compared with those cooked at HIGH $(P=0.002,0.001,0.018$, respectively). All 4 furans had higher $(P<0.040)$ aroma compound values when steaks were cooked at a HIGH grill temperature compared with LOW. Furthermore, 2-furan methanol and 2-octylfuran were higher in THICK than THIN steaks. This would be expected because furans are Maillard reaction products and would have brown, cooked sugar, or caramel aroma descriptors (Kerth and Miller, 2015). Sepulveda et al. (2019) indicated that cooking methods that supported the production of Maillard reaction products resulted in increased concentrations of furan volatile aroma compounds.

Six of the 8 ketone volatile aroma compounds (which all tend to have fruity aroma descriptors) were increased when steaks were cooked at HIGH compared with LOW $(P<0.048)$. Additionally, 4-hydroxy-4methyl-2-pentanone values were higher $(P=0.001)$ in THIN compared with THICK, but 4-methyl-2-pentanone values were lower $(P=0.001)$ in THIN than THICK; it was only present in THICK steaks cooked $\mathrm{HIGH}$ as the other treatment combinations were not different $(P>0.05)$ from zero. Furthermore, all 4 of the pyrazines, which tend to smell nutty, roasted, coffee, or meaty, were higher in steaks cooked at HIGH compared with those cooked at LOW grill temperatures $(P<0.045)$. Additionally, 2-ethyl-5-methyl pyrazine, 2-methyl-6-(1-propenyl) pyrazine, and 2,3-diethyl-5methyl pyrazine were all higher $(P<0.048)$ in THICK steaks compared with THIN; in fact, 2,3-diethyl-5methyl pyrazine was only present $(P<0.05)$ in THICK steaks cooked HIGH. Gardner and Legako (2018) cooked steaks to different degrees of internal doneness and found that the higher degrees of doneness, resulting from longer cooking times, produce higher amounts of various pyrazines. This also agrees with Wall et al. (2019), who reported that pyrazines were significantly higher in steaks grilled at $232^{\circ} \mathrm{C}$ compared with either $205^{\circ} \mathrm{C}$ or $177^{\circ} \mathrm{C}$, thus indicating that severe heat is required to develop pyrazines.

The sulfur-containing compound 1-acetylthiazole was found to be higher in THIN steaks than THICK, whereas methanethiol was higher $(P=0.001$ and 
0.049 , respectively) in THICK compared with THIN, but neither were affected $(P>0.82)$ by grill temperature. The volatile compound $1 \mathrm{H}$-indole (fecal) did not differ between steak thickness when grilled LOW, but within HIGH grill temperatures, THICK steak values were higher than THIN steak values $(P=$ 0.002). The 1-ethyl-1H-pyrrole, 1-methyl-1H-pyrrole, and 2-methyl-pyridine compounds were all only found in THICK, HIGH steaks $(P=0.001)$. The 1 -octene (gasoline) was higher $(P=0.005)$ in THIN steaks, whereas pyridine $(P=0.029$; penetrating aroma) and styrene $(P=0.037$; sweet, balsamic) were higher in THICK steaks. Ethylbenzene (gasoline), pyridine, and styrene were higher when the grill temperature was HIGH compared with LOW $(P=0.007,0.005$, and 0.037 , respectively).

These findings along with others throughout the present study are bolstered by the findings of Jousse et al. (2002). They showed a simplified scheme, based on the original work of Hodge (1953), indicating the kinetics of the Maillard reaction and the energy required for each of at least 11 basic reactions that classify groups of volatiles into their respective groups and corresponding rate constants. Furans are 5 th or 7 th order and pyrazines are 10th order reactions requiring a great deal of energy to arrive at these volatile compounds, with melanoidins (brown color) being the last thing produced in their model system. Yoo et al. (2020) reported that reducing sugars decreased and Maillard reaction products increase when steaks were seared on a $250^{\circ} \mathrm{C}$ pan compared with roasting in a $180^{\circ} \mathrm{C}$ oven. Our research shows that a long time and/or high temperature is necessary during the cooking process to develop compounds such as pyrazines that are instrumental in producing the beef identity and brownroasted flavor aromatics.

In an interaction of steak thickness and quality grade, 2-octene was only found in THIN Select steaks (Figure 3$)$. Trimethyl pyrazine was lower $(P<0.05)$ in THIN than THICK steaks within the Select quality grade, but steak thickness did not affect $(P>0.05)$ trimethyl pyrazine in Choice quality grade. Figure 4 shows that benzene acetaldehyde was significantly higher $(P<0.05)$ in USDA Select LOW steaks compared with all other treatment combinations. HIGH Select steaks had more $(P<0.05)$ 4-hydroxybenzoic acid than LOW Select steaks but were not affected by grilling temperature within USDA Choice. Finally, 5-methyl-2-furan carboxaldehyde was only found in HIGH Choice steaks $(P<0.05)$, as the other treatment combinations were not different $(P>0.05)$ than zero.

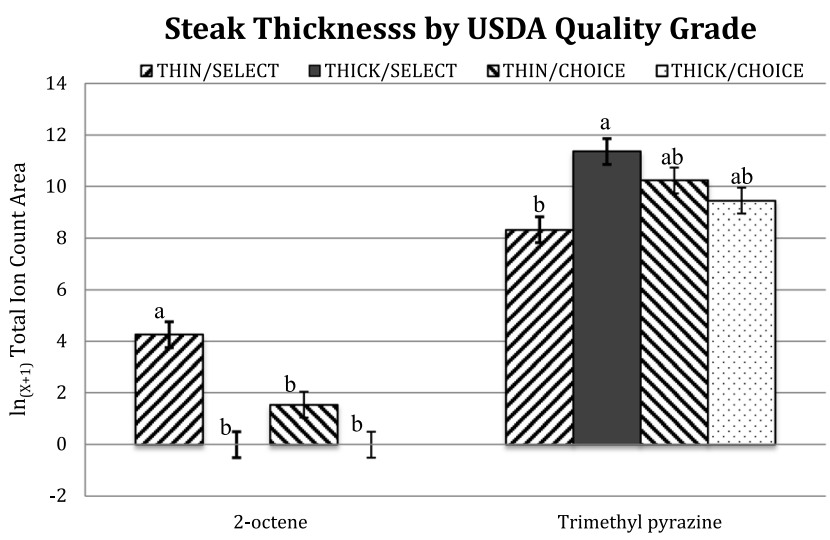

Figure 3. Steak thickness by USDA Quality Grade interaction effects on volatile compounds. THIN $=1.3-\mathrm{cm}$-thick steaks, THICK $=3.8-\mathrm{cm}$ thick steaks, SELECT $=$ USDA Select Quality Grade, $\mathrm{CHOICE}=$ USDA Choice Quality Grade. ${ }^{\mathrm{a}, \mathrm{b}}$ Bars with different letters indicate steak thickness by USDA Quality Grade interaction least-squares means within a trait are significantly different $(P<0.05)$.

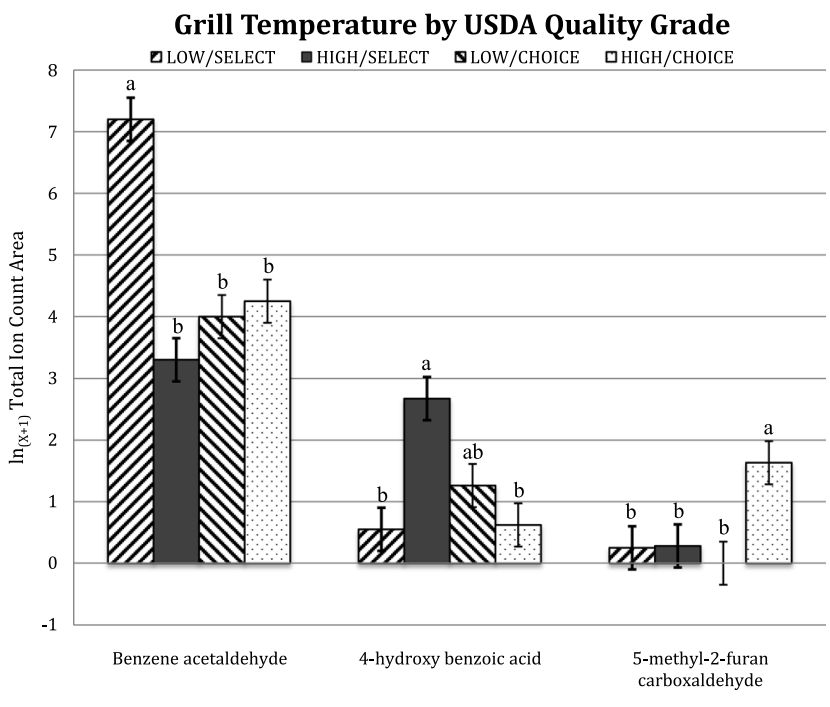

Figure 4. Grill temperature by USDA Quality Grade interaction effects on volatile compounds. $\mathrm{LOW}=177^{\circ} \mathrm{C}$ grill temperature, $\mathrm{HIGH}=$ $232^{\circ} \mathrm{C}$ grill temperature, SELECT $=$ USDA Select Quality Grade, CHOICE = USDA Choice Quality Grade. ${ }^{\mathrm{a}, \mathrm{b}}$ Bars with different letters indicate grill temperature by USDA Quality Grade interaction least-squares means within a trait are significantly different $(P<0.05)$.

\section{Conclusions}

The identification of aroma volatiles that drive consumer liking and aromas associated with descriptive flavor attributes are important steps in understanding beef flavor chemistry. By identifying major aroma volatile compounds and how and when they are formed, the ability to identify conditions that maximize beef flavor and consumer acceptability, especially during cooking, can be used to improve consumer satisfaction with beef. 


\section{Acknowledgements}

Funding for this research was provided by the Beef Checkoff.

\section{Literature Cited}

AMSA. 2015. Research guidelines for cookery, sensory evaluation, and instrumental tenderness measurements of meat. 2nd ed. American Meat Science Association, Champaign, IL.

Ba, H. V., I. Hwang, D. Jeong, and A. Touseef. 2012. Principle of meat aroma flavors and future prospect. In: I. Akyar, editor, Latest research into quality control. IntechOpen, London, UK. p. 145-176. https://doi.org/10.5772/51110.

Berry, B. W., and M. E. Bigner. 1995. Use of grilling and combination broiler-grilling at various temperatures for beef loin steaks differing in marbling. Food. Res. Int. 8:65-74. https://doi.org/10.1111/j.1745-4506.1995.tb00077.x.

Brooks, J. C., J. B. Belew, D. B. Griffin, B. L. Gwartney, D. S. Hale, W. R. Henning, D. D. Johnson, J. B. Morgan, F. C. Parrish, Jr., and J. O. Reagan. 2000. National Beef Tenderness Survey1998. J. Anim. Sci. 78:1852-1860. https://doi.org/10.2527/ 2000.7871852x.

Burdock, G. A. 2010. Fenaroli's handbook of flavor ingredients. 6th ed. CRC Press/Taylor and Francis, Boca Raton, FL.

Cadwallader, K. R., Q. Tan, F. Chen, and S. P. Meyers. 1995. Evaluation of the aroma of cooked spiny lobster tail meat by aroma extract dilution analysis. J. Agr. Food Chem. 43:2432-2437. https://doi.org/10.1021/jf00057a022.

Cross, H. R., M. S. Stanfield, and E. J. Koch. 1976. Beef palatability as affected by cooking rate and final internal temperature. J. Anim. Sci. 43:114-121. https://doi.org/10.2527/jas1976. $431114 \mathrm{x}$.

Feng, R., Y. Bao, D. Liu, S. Zhang, Y. Wang, D. Chen, and P. Zhou. 2020. Steam-assisted roasting inhibits formation of heterocyclic aromatic amines and alters volatile flavour profile of beef steak. Int. J. Food Sci. Tech. 55:3061-3072. https://doi.org/ 10.1111/ijfs. 14570 .

Gardner, K., and J. F. Legako. 2018. Volatile flavor compounds vary by beef product type and degree of doneness. J. Anim. Sci. 96:4238-4250. https://doi.org/10.1093/jas/sky287.

Gardner, T., K. R. Vierck, S. Martini, K. Allen, H. Ban, R. K. Miller, C. R. Kerth, and J. F. Legako. 2020. Thermophysical properties of beef steaks of varying thicknesses cooked with low and high grill surface temperatures. Meat Muscle Biol. 4:1-11. https:// doi.org/10.22175/mmb.10916.

Glascock, R. A. 2014. Beef flavor attributes and consumer perception. M.S. thesis, Texas A\&M Univ., College Station, TX.

Guelker, M. R., A. N. Haneklaus, J. C. Brooks, C. C. Carr, R. J. Delmore, Jr., D. B. Griffin, D. S. Hale, K. B. Harris, G. G. Mafi, D. D. Johnson, C. L. Lorenzen, R. J. Maddock, J. N. Martin, R. K. Miller, C. R. Raines, D. L. VanOverbeke, L. L. Vedral, B. E. Wasser, and J. W. Savell. 2013. National Beef Tenderness Survey-2010: Warner-Bratzler shear force values and sensory panel ratings for beef steaks from United States retail and food service establishments. J. Anim. Sci. 91:1005-1014. https://doi.org/10.2527/jas.2012-5785.
Hodge, J. E. 1953. Dehydrated foods, chemistry of browning reactions in model systems. J. Agr. Food Chem. 1:928-943. https://doi.org/10.1021/jf60015a004.

Jousse, F., T. Jongen, W. Agterof, S. Russell, and P. Braat. 2002. Simplified kinetic scheme of flavor formation by the Maillard reaction. J. Food Sci. 67:2534-2542. https://doi.org/10.1111/ j.1365-2621.2002.tb08772.x.

Kerth, C. 2016. Determination of volatile aroma compounds in beef using differences in steak thickness and cook surface temperature. Meat Sci. 117:27-35. https://doi.org/10.1016/j.meatsci. 2016.02.026.

Kerth, C. R., and R. K. Miller. 2015. Beef flavor: A review from chemistry to consumer. J. Sci. Food Agr. 95:2783-2798. https://doi.org/10.1002/jsfa.7204.

Kim, S., J. Chen, T. Cheng, A. Gindulyte, J. He, S. He, Q. Li, B. A. Shoemaker, P. A. Thiessen, B. Yu, L. Zaslavsky, J. Zhang, and E. E. Bolton. 2019. PubChem in 2021: New data content and improved web interfaces. Nucleic Acids Res. 49:D1388D1395. https://doi.org/10.1093/nar/gkaa971.

Knize, M. G., F. A. Dolbeare, K. L. Carroll, D. H. Moore II, and J. S. Felton. 1994. Effect of cooking time and temperature on the heterocyclic amine content of fried beef patties. Food Chem. Toxicol. 32:595-603. https://doi.org/10.1016/0278-6915(94) 90002-7.

Legako, J. F., J. C. Brooks, T. G. O’Quinn, T. D. J. Hagan, R. Polkinghorne, L. J. Farmer, and M. F. Miller. 2015. Consumer palatability scores and volatile beef flavor compounds of five USDA quality grades and four muscles. Meat Sci. 100:291-300. http://doi.org/10.1016/j.meatsci.2014.10.026.

Luckemeyer, T. J. 2015. Beef flavor attributes and consumer perception on light beef eaters. M.S. thesis, Texas A\&M Univ., College Station, TX.

Meilgaard, M. C., B. T. Carr, and G. V. Civille. 2006. Sensory evaluation techniques. CRC Press, Boca Raton, FL.

Miller, R. K., C. R. Kerth, M. C. Berto, H. L. Laird, and J. W. Savell. 2019. Steak thickness, cook surface temperature and quality grade affected top loin steak consumer and descriptive sensory attributes. Meat Muscle Biol. 3:467-478. https://doi. org/10.22175/mmb2018.07.0020.

Mottram, D. S. 1998. Flavour formation in meat and meat products: A review. Food Chem. 62:415-424. http://doi.org/10.1016/ S0308-8146(98)00076-4.

Sepulveda, C. A., A. Garmyn, J. Legako, and M. F. Miller. 2019. Cooking method and USDA Quality Grade affect consumer palatability and flavor of beef strip loin steaks. Meat Muscle Biol. 3:375-388. https://doi.org/10.22175/mmb2019.07.0031.

Shahidi, F. 1998. Flavor of meat, meat products, and seafoods. 2nd ed. Blackie Academic and Professional, London, UK.

Skog, K., G. Steineck, K. Augustsson, and M. Jägerstad. 1995. Effect of cooking temperature on the formation of heterocyclic amines in fried meat products and pan residues. Carcinogenesis 16:861-867. https://doi.org/10.1093/carcin/16.4.861.

Small, D. M., M. Jones-Gotman, R. J. Zatorre, M. Petrides, and A. C. Evans. 1997. Flavor processing: More than the sum of its parts. Neuroreport 8:3913-3917. https://doi.org/10.1097/ 00001756-199712220-00014.

USDA. 1996. United States standards for grades of slaughter cattle. United States Department of Agriculture, Washington, DC. 
Van Den Dool, H., and P. D. Kratz. 1963. A generalization of the retention index system including linear temperature programmed gas-liquid partition chromatography. J. Chromatogr. A 11:463-471. https://doi.org/10.1016/ S0021-9673(01)80947-X.

Wall, K. R., C. R. Kerth, R. K. Miller, and C. Alvarado. 2019. Grilling temperature effects on tenderness, juiciness, flavor and volatile aroma compounds of aged ribeye, strip loin, and top sirloin steaks. Meat Sci. 150:141-148. https://doi. org/10.1016/j.meatsci.2018.11.009.

Yoo, J. H., J. W. Kim, H. I. Yong, K. H. Baek, H. J. Lee, and C. Jo. 2020. Effects of searing cooking on sensory and physicochemical properties of beef steak. Food Sci. Anim. Res. 40:44-54. https://doi.org/10.5851/kosfa.2019.e80. 